\title{
Evaluation of interface adhesion of hot-dipped zinc coating on TRIP steel with tensile testing and finite element calculation
}

\author{
G. M. Song ${ }^{1}$, J. Th. M. De Hosson ${ }^{2}$, W. G. Sloof ${ }^{1} \&$ Y. T. Pei ${ }^{3}$ \\ ${ }^{1}$ Department of Materials Science and Engineering, \\ Delft University of Technology, The Netherlands \\ ${ }^{2}$ Department of Applied Physics, \\ Zernike Institute for Advanced Materials, \\ University of Groningen, The Netherlands \\ ${ }^{3}$ Department of Advanced Production Engineering, \\ Engineering and Technology Institute Groningen, \\ University of Groningen, The Netherlands
}

\begin{abstract}
In this work, a methodology for the determination of the interface adhesion strength of zinc coating on TRIP steel is present. This method consists of a conventional tensile test in combination with finite element calculation. The relation between the average interface crack length and the applied tensile stress is determined on the partially delaminated coating with in-situ tensile test. The delamination process of zinc coating on steel substrate is simulated by using a two-grain finite element model with different interface adhesion strengths. By comparing the experimental observation with the finite element calculations, the interface adhesion strength is estimated. The interface adhesion strength of the zinc coating on transformation induced plasticity (TRIP) steel is found as high as $160 \mathrm{MPa}$. The influences of microstructural parameters of zinc coating including zinc grain orientation and grain size on the delamination behavior of the zinc coating are also analyzed with the finite element model.

Keywords: finite element modeling, interface cracking, adhesion strength, hotdipped zinc coatings, TRIP steel.
\end{abstract}




\section{Introduction}

Zinc coating is widely used to prevent the corrosion of steels [1-3]. Formability and the damage resistance of $\mathrm{Zn}$ coating strongly depend on its adhesion to a steel substrate $[4,5]$. Although many methods have been developed for the assessment of adhesion strength of coatings, such as tearing-off [6, 7], peelingoff [8], bending $[9,10]$, indentation $[11]$, scratch test $[12,13]$, and shear $[14,15]$, the application of the methods of tearing-off, peeling-off, bending and shear depends on the strength of glue used to bond the coating [6, 16]. Another problem about the measured shear strength is that the stress at the interface is not distributed uniformly [14]. High stress concentrations arise at the coating edges, such as the single lap tensile method [16]. The maximum stress at the edges, which is decisive for the delamination, is dependent on the overlap area size. Thus, the measured average adhesion strength is not a material property. The results usually show large scattering and must be viewed qualitatively rather than quantitatively. For brittle coating/substrate systems, detailed studies of coating delamination have been made, and an extensive overview is given by Hutchinson and Suo [17], and more recently by Freund and Suresh [6]. On the contrary, however, the comprehensive knowledge about the coating adhesion of a ductile coating on a ductile substrate, as being the case for zinc coatings on steel, is lacking due to the complicated elasto-plastic mechanical behavior in the soft zinc coating/steel interface region during deformation [18, 19]. Analytical methods are generally not feasible for the explanation of the interface crack behavior between a ductile coating and ductile substrate.

Currently developed $\mathrm{CMnP}$ transformation induced plastic (TRIP) steel $(0.2 \mathrm{wt} \% \mathrm{C}, 1.5 \mathrm{wt} \% \mathrm{Mn}, 0.1 \mathrm{wt} \% \mathrm{P}, 0.1 \mathrm{wt} \% \mathrm{Si})$ is a very promising material for the automotive industry because it combines a high strength with sufficient ductility $[20,21]$. Compared with the typical CMnSi $(0.2 \mathrm{wt} \% \mathrm{C}, 1.5 \mathrm{wt} \% \mathrm{Mn}$, $1.5 \mathrm{wt} \% \mathrm{Si}$ ) TRIP steel, a small amount of $\mathrm{P}$ in CMnP TRIP steel effectively suppresses the formation of stable $\mathrm{Mn}-\mathrm{Si}$ oxides at the steel surface when it strengthens the steel matrix $[22,23]$. As a result, the wettability of the steel surface in molten zinc bath during hot-dipping galvanizing and consequent galvanizing quality are greatly improved $[23,24]$. CMnP TRIP steel is expected to be potentially compatible with the currently used continuous hot-dip galvanizing process.

Considering the application of the hot-dipping galvanized CMnP TRIP steel sheets as panels of cars, a good adhesion of zinc coating to the steel substrate is required for the formability of this material. To this end, fundamental research about the microstructure and adhesion of zinc coatings on the steel substrates are necessary. Unfortunately, to date, there is no method available to evaluate the adhesive quality of the metallic zinc coating on steel. Additionally, the relation between coating adhesion and the microstructural parameters of the coating such as zinc grain size and orientation is unclear.

The present work concentrates on partial delamination of zinc coating that occurs during tensile testing, providing an opportunity to probe the adhesive fracture of the zinc coating/steel interface. Therefore, a methodology for the 
determination of coating adhesion strength by tensile testing is expected to be established. To attain this aim, a finite element model for $\mathrm{Zn}$ coating delamination from metal substrate is developed to study the coating adhesion of zinc coated TRIP steels. The influence of the zinc grain size and grain orientation on the coating adhesion will be analyzed with this model. Scanning electron microscopic (SEM) observations of the coating delamination during in situ tensile testing of zinc coated TRIP steel sheet were used to verify the validity of the model. The adhesion strength of the zinc coating to TRIP steel is obtained by comparing the experimental observations to the finite element calculation of the interface crack of zinc coating on TRIP steel.

\section{Experimental}

The cold-rolled CMnP TRIP steel sheets $(220 \times 110 \times 1 \mathrm{~mm})$ (provided by Tata Steel Europe, IJmuiden, the Netherlands) was annealed in a 5 vol. $\% \mathrm{H}_{2}$ in $\mathrm{N}_{2}$ atmosphere at $830^{\circ} \mathrm{C}$ and then cooled to $400^{\circ} \mathrm{C}$ for $2 \mathrm{~min}$, prior to hot-dipping at $460^{\circ} \mathrm{C}$ for $2 \mathrm{~s}$ in a molten zinc bath containing $0.2 \mathrm{wt} . \% \mathrm{Al}$ with a laboratory RHESCA simulator. The sheet was drawn out of the zinc bath under a steam of $\mathrm{N}_{2}$ gas to remove excess liquid zinc and to cool down to room temperature. The final zinc coating thickness was about $10 \mu \mathrm{m}$ with an average zinc grain size of about $100 \mu \mathrm{m}$.

The zinc coating adhesion was studied by in-situ tensile testing using a $5 \mathrm{kN}$ microtester (DEBEN, UK), which was amounted in the vacuum chamber in a scanning electron microscope (SEM) with a field emission gun (JEOL JSM $6500 \mathrm{~F}$ ). To this end, 'dog-bone' tensile samples of the galvanized steel sheet were used with the tested area of the material having the dimensions $13 \times 5 \times 1 \mathrm{~mm}$. Cracking behavior of the coating during tensile testing was recorded with a digital video camera in the SEM. Cross sections of the partially delaminated zinc coating of the tensile-tested samples were prepared to determine the location and extent of the interface fracture and crystallographic orientation of the $\mathrm{Zn}$ grains. Electron backscatter diffraction (EBSD) (HKL Technology, Denmark) was employed to determine the crystallographic orientation of the $\mathrm{Zn}$ grains.

For a quantitative analysis of the fracture behavior of the zinc coating, the crack opening, $2 u$, and the interface crack length, $L$, were determined from the SEM observations; see Fig. 1. The crack opening was observed as a function of the applied strain, $\varepsilon$, both in top view and on the cross sections of the deformed sample. Each average value of the crack gap, as determined from the observation in top view, was obtained from about 30 cracks by measuring the gap of each crack at about 10 locations. An average value of the crack opening was also determined from the observations in cross section; together with an average value for the interface crack length. For each value of the applied strain more than 20 cracks were analyzed from a series of cross sections. The average crack opening as determined in top view (loaded condition) and in cross section (unloaded condition) were the same within the experimental error. 


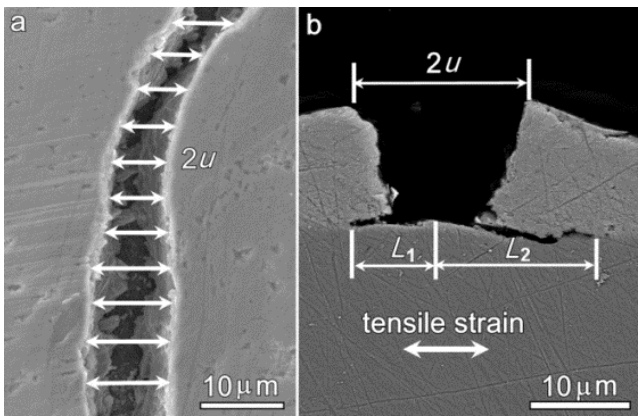

Figure 1: Cracking of Zn grains under tensile deformation: (a) top view; and (b) cross sectional view. The crack opening $2 u$ and interface crack length $L$ are indicated.

\section{Problem formulation}

Considering a typical hot-dip galvanized zinc coated steel system, a two dimensional plane strain finite element model was adopted, which comprised two flat half grains (A and B) on top of a continuous substrate representing the zinc coating on the steel substrate; see Fig. 2. Both the coating and substrate are modeled as isotropic elastoplastic materials with large non-linear behavior. This model was inspired by the observed fracture behavior of zinc coating during uniaxial tensile testing, which occurred exclusively along the zinc coating grain boundaries followed by fracture along the zinc coating/steel substrate interface (cf. Section 4.1). The elasto-plastic properties for both zinc and steel are described with uniaxial stress-strain curves [25]:

$$
\begin{gathered}
\sigma=E \varepsilon \quad\left(\varepsilon \leq \varepsilon_{Y}\right) \\
\sigma=\sigma_{Y}\left(1+\frac{E}{\sigma_{Y}}\left(\varepsilon-\varepsilon_{Y}\right)\right)^{n} \quad\left(\varepsilon>\varepsilon_{Y}\right)
\end{gathered}
$$

where $\sigma$ and $\varepsilon$ are the true stress and the true strain, respectively; $E, \sigma_{\mathrm{Y}}, \varepsilon_{\mathrm{Y}}$ and $n$ denote the Young's modulus, yield stress, yield strain and work hardening index.

Extensively experimental observations show that the zinc grain boundaries are the sources of crack initiation and crack prior to the coating delamination during tensile testing. No transgranular cracking is observed of the zinc during the tensile testing process (cf. Section 4.1). Because of intergranular failure the zinc grain boundaries are thought as weaker path for crack propagation than the zinc coating/steel interface and the zinc grain interior. In this study, the fracture along the grain boundary is simulated by separating the two grains if the flow stress at the grain boundary becomes higher than a crack displacement criterion representing the strength of zinc grain boundary.

It is widely accepted that the coating/substrate interface cracking is driven by mixed-mode failure of interfacial shear stress and normal stress perpendicular to the interface at the interface crack tip [6], namely $\sigma_{y}$ and $\tau_{x y}$. Here, the maximum 
principal stress, $\sigma_{\max }$, at the crack tip is taken as the criterion for crack propagation along the interface [26]:

$$
\sigma_{\max }=\frac{\sigma_{x}+\sigma_{y}}{2}+\sqrt{\left(\frac{\sigma_{x}-\sigma_{y}}{2}\right)^{2}+\tau_{x y}^{2}}
$$

which comprises the normal stress, $\sigma_{y}$, perpendicular to the interface, the shear stress, $\tau_{x y}$, along the interface and tensile stress, $\sigma_{x}$, parallel to the interface. Both $\sigma_{y}$ and $\tau_{x y}$ at the crack tip (where $\sigma_{x}=\left.0\right|_{x=0}$ ) may cause the interface crack to propagate with so-called mixed mode I and II [17]. The fracture along the zinc coating/steel interface was simulated with the finite element model by deleting the elements in the coating where the maximum principal stress was larger than a critical value representing the interface strength in the numerical calculation, i.e. the delamination process of the coating along the interface was simulated as the cohesive failure in the coating along the interface where concentrated stress were induced by the non-uniform deformation at the interface.
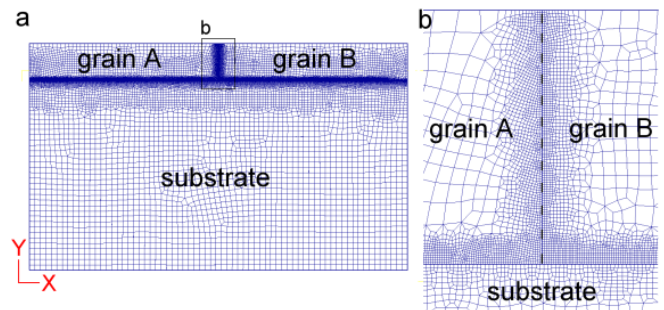

Figure 2: 2D plane strain finite element model composed of two half grain A and B on steel substrate: (a) overview; (b) close view at the grain boundary.

Zinc grain exhibits significant anisotropic properties due to its hexagonal crystal structure, e.g. the Young's modulus along [0001] orientation direction is only one-third of that along the orientation parallel to the basal (0001) plane [27, 28]. The influence of the crystallographic orientation of zinc grain on the coating delamination is studied by setting different mechanical parameters for "isotropic" zinc grains A and B (it will be convenient for the finite element calculation that the mechanical performance of zinc is assumed to be isotropic). By changing the geometric parameters of zinc grain A and B, the influences of grain size are investigated.

In agreement with the average zinc coating thickness and grain size, the width and the height of half grain $A$ and $B$, were taken as $50 \mu \mathrm{m}$ and $10 \mu \mathrm{m}$, respectively. Considering the influence of the thin coating on the stress-strain field in the steel substrate will become weaker and weaker with increasing distance from the coating/steel interface; the thickness of the steel substrate is taken as $50 \mu \mathrm{m}$ in our model, and the width is set as $100 \mu \mathrm{m}$. The left side of the box (Fig. 2) was fixed on the Y-axis, and the right side of the box moved along the X-axis. The box was meshed into about 25,000 elements with 4 nodes. The deformation and interface delamination behavior of zinc coating on steel sheet 
upon tensile loading were simulated with Deform 2D finite element software package [29].

The mechanical parameters: yield strength, Young's modulus and work hardening index of the zinc grain were extracted from load-depth curves as measured on various zinc grains with nanoindention [28], and $\sigma_{\mathrm{Y}}=85 \mathrm{MPa}, E=80$ $\mathrm{GPa}, n=0.14$ are adopted as average values for the zinc grains. The parameters: $\sigma_{\mathrm{Y}}=316 \mathrm{MPa}, E=205 \mathrm{GPa}, n=0.225$ for the TRIP steel substrate were measured with uniaxial tensile testing.

In this numerical calculation, the two zinc grains will separate if the stress at the grain boundary is higher than $75 \mathrm{MPa}$ that represents the intrinsic strength of zinc grain boundary under pure tension, as experimentally measured.

Numerical calculations of the coating delamination process were performed with different values of interface strength and compared the experimental data.

\section{Results and discussion}

\subsection{Zinc coating cracking behavior}

The in situ SEM observation on the zinc coating cracking behavior under tensile loading shows that cracks first occur along the zinc coating grain boundaries (Fig. 3(a)). And then these cracks crossed through the zinc coating thickness and were arrested at the interface with steel substrate, resulting in a segmented fractured coating (Fig. 3(b)). As applied average tensile strain exceeded about $4 \%$, massive cracking along zinc grain boundaries occurred. As a result, the size of the segmented coating is almost the same as the zinc grain size (about $100 \mu \mathrm{m}$ in segment length). The presence of microvoids and microcracks at zinc grain boundaries after hot dipping is considered responsible for weaker grain boundaries; see Fig. 4 . The voids may be caused by the large volume shrinkage (8.26 vol.\%) upon solidification of the zinc, whereas the microcracks should be induced by the large thermal misfit between the solid zinc coating and the steel substrate after cooling from the solidification temperature to room temperature.
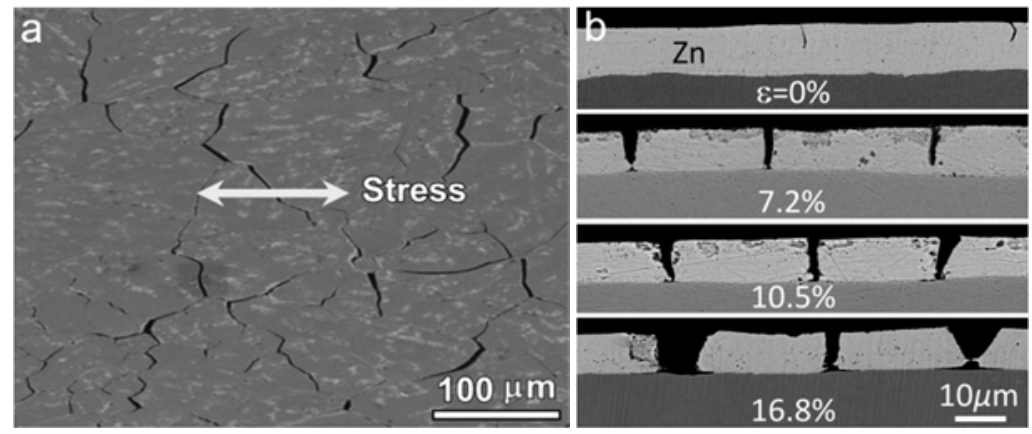

Figure 3: Grain boundary and interface fracture of $\mathrm{Zn}$ coating on TRIP steel under tensile stress: (a) top view; and (b) cross-sectional view (SEM). 


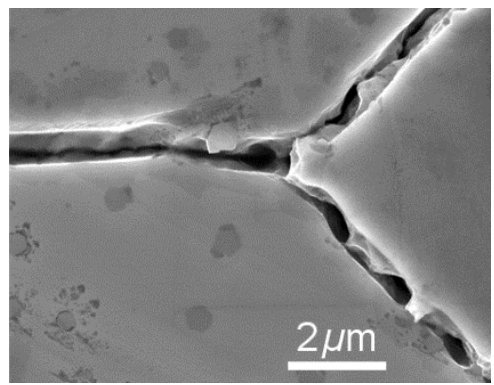

Figure 4: Microvoids and microcracks at grain boundaries of hot-dipped $\mathrm{Zn}$ coating on TRIP steel.

Stress concentration was induced in the zinc coating at the interface with the substrate near the edges of the zinc grains [30], which gave rise to subsequent cracking along the zinc coating/steel substrate interface. With increasing tensile load, the stresses at the interface increased and the cracks propagated along the interface and partial delamination of the zinc coating occurred; see Fig. 5(a). The stress distributions at the edge have been calculated with the finite element method, as shown in Fig. 5(b).
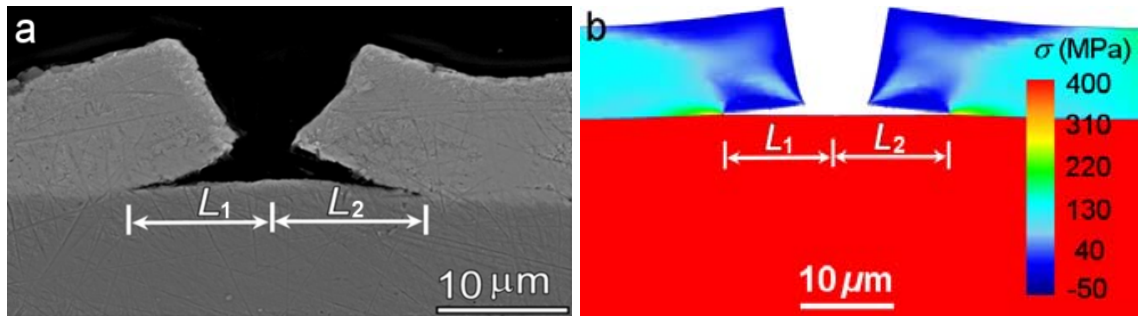

Figure 5: Interfacial fracture of two zinc coating grains with crack length $L$ under 16.8\% tensile strain: (a) SEM observation; and (b) FEM simulation.

As long as the interface crack length is small compared with the diameter of the zinc grains, the magnitude of the stress values at the interface crack tip remain practically constant. Thus, the interface crack will propagate when the principal stress at the crack tip exceeds a critical value. As a result, this critical stress value should be taken as a quantitative measure of the interface adhesion strength for the mixed mode state of stress considered.

The average crack length, $L$, along the coating/steel interface versus $\varepsilon$ is plotted in Fig. 6(a). Zn grains start to delaminate if the deformation exceeds an initial strain $\left(\varepsilon_{0}\right)$ of $\sim 4 \%$. Subsequently, the interface crack length increases approximately linearly with the applied tensile strain, which can be approximately expressed as $L=1.47\left(\varepsilon_{\mathrm{app}}-\varepsilon_{0}\right)$. In addition, the calculated interface crack length as a function of the strain for different values of interface adhesion strength is plotted in Fig. 6(b). Comparing the experimental and calculated data 
indicated that the adhesion strength of the hot-dipped zinc coating on $\mathrm{CMnP}$ TRIP steel is about $160 \mathrm{MPa}$, slightly lower than the adhesion strength of hotdipped zinc coating on IF steel [31].
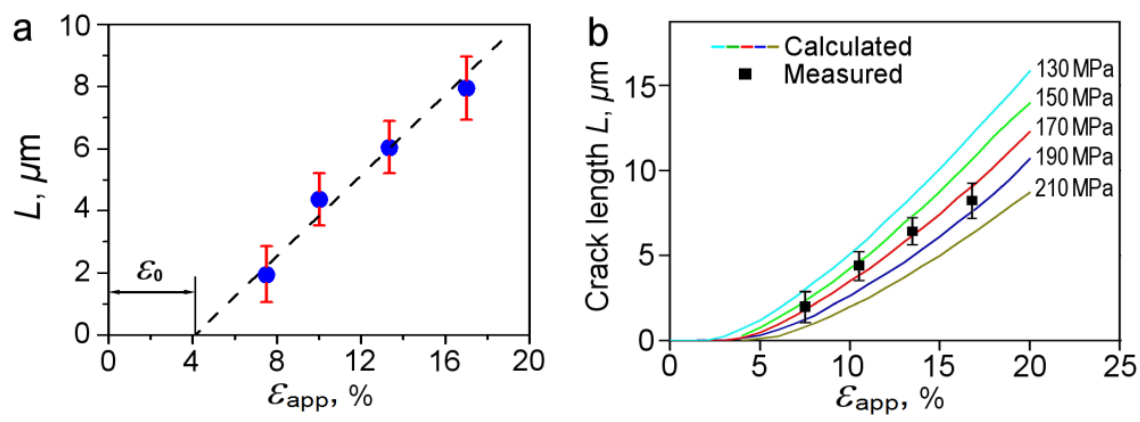

Figure 6: (a) Measured average interfacial crack length $(L)$ versus applied strain; (b) Calculated interfacial crack length for different adhesion strengths of hot-dipped zinc coating on TRIP steel.

\subsection{Comparison between calculated and experimental measured results}

The whole coating cracking process is simulated with the finite element model, and compared with a series of experimental observations on the cross sections of zinc coated TRIP steel sample with SEM after applying different tensile strains. Fig. 5 shows such a comparison between the experimental and calculated cross sections of the partial delaminated zinc grains with similar orientations on steel substrate after applying a same strain of $16.8 \%$. The calculation is performed by adopting the interface adhesion strength of $160 \mathrm{MPa}$. A striking resemblance exists between the microscopical observation and the result of the finite element modeling.

\subsection{Effect of grain orientation}

The hexagonal $\alpha$-zinc grain crystal structure results in significantly different mechanical properties along different crystallographic orientations. Due to the significant anisotropy of the mechanical properties of zinc grain, remarkable differences in the delamination behavior were observed among variously orientated zinc grains. Thus, under the same applied strain, the flow stress levels in the [0001] direction will be much lower than that perpendicular to the [0001] direction. For example, in Fig. 7(a) the angle of [0001] crystallographic direction of the left $\alpha-\mathrm{Zn}$ grain with respect to the tensile load direction is $48^{\circ}$, and that for the right grain is $81^{\circ}$ (as determined with EBSD). The interface crack length for the left grain is only $0.5 \mu \mathrm{m}$, which is much smaller than the interface crack length for the right grain, viz. $6.0 \mu \mathrm{m}$.

The interface fracture process for two differently oriented adjacent zinc grains (A and B) on TRIP steel substrate was simulated, assuming the same adhesion strength for the two zinc grains. The different orientations for both grains were 
included in the numerical calculations by considering the anisotropy of the mechanical properties of the grains $\mathrm{A}$ and $\mathrm{B}: \sigma_{\mathrm{Y}}=55 \mathrm{MPa}, E=50 \mathrm{GPa}, n=0.14$ for grain $\mathrm{A}$, and $\sigma_{\mathrm{Y}}=115 \mathrm{MPa}, E=125 \mathrm{GPa}, n=0.15$ for grain $\mathrm{B}$. The anisotropic mechanical characterization along different zinc crystal orientation is expressed by giving different mechanical parameters to the grains A and B in this study. The calculated stress field shows that the stress levels at the edge of grain B near the interface with the substrate become much larger upon tensile loading than those at the edge of grain A. Consequently, the stresses at the interface with grain B exceed the adhesion strength at lower applied tensile strains than those at the interface with grain A. Thus, fracture occurs along the interface between grain B and the steel substrate. This is demonstrated in Fig. 7(b), which shows a result of the numerical simulation for two differently oriented zinc grains on a steel substrate. An experimental observation confirms this result: two differently oriented adjacent grains shows that large delamination of the zinc crystal grain with its basal plane nearly parallel to the interface with the substrate occurred upon applying a tensile strain of about $13 \%$.
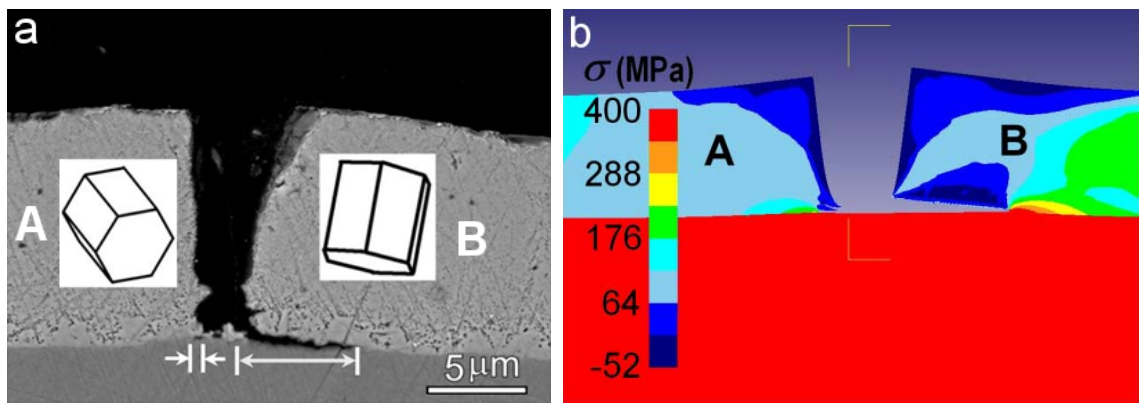

Figure 7: Interface fracture of two $\mathrm{Zn}$ coating grains $\mathrm{A}$ and $\mathrm{B}$ with the different orientations as indicated by the unit cells: (a) SEM observation; and (b) FEM simulation with a coating adhesion strength of $160 \mathrm{MPa}$.

\subsection{Effect of grain size}

The experimental observation on the cross-section of the zinc coated steel sample after tensile deformation shows that the delamination of the coating depends on grain size; see Fig. 8(a). From a statistical point of view, the larger a $\mathrm{Zn}$ coating grain, the longer the interface crack length as long as fracture along the grain boundaries precedes fracture along the coating/substrate interface. The larger the grains, the more the deformation will be constrained to the edge of the grain near the interface with the substrate; consequently, higher stresses will develop at the edge of the grain near the interface with the substrate. Thus, delamination along the interface will be larger for large grains than for small grains for the same applied strain and interface adhesion strength. This grain size 
effect was simulated by taking the half-lengths of grains A and B, as $20 \mu \mathrm{m}$ and $80 \mu \mathrm{m}$, respectively, see Fig. 8(b). Indeed, the interface crack length increased much less for the small grain (A) than for the large grain (B).
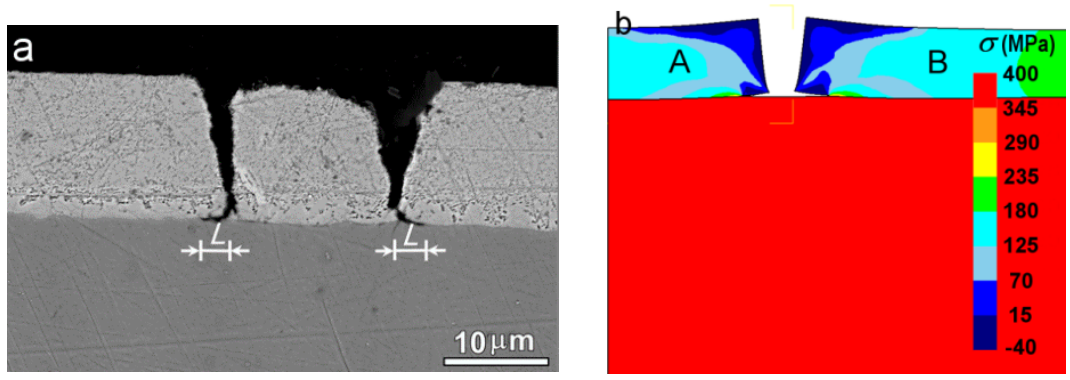

Figure 8: Effect of Zn grain size on the interface fracture length of hot-dipped $\mathrm{Zn}$ coating on TRIP steel: (a) SEM observation; and (b) FEM simulation with the coating adhesion strength of $160 \mathrm{MPa}$.

\section{Conclusions}

The present work shows that the adhesion of elasto-plastic coating on elastoplastic substrate can be determined using conventional tensile testing combined with finite element calculation. Being an example of the application of the methodology, the adhesion strength of hot-dipped zinc coating on TRIP is determined from the average crack opening as observed with SEM during in situ tensile testing. A (practically linear) relation exists between the applied strain and the average interface crack length. In combination with FEM simulations, the adhesion strength of the coating is estimated at about $160 \mathrm{MPa}$.

The result of finite element calculation shows that coating delamination will be mitigated as the grain orientation [0001] tends to parallel to the zinc coating/steel interface. A small grain size is effective for preventing coating delamination. The theoretic prediction is verified with the experimental results of hot-dip galvanized zinc coating on TRIP steel. These results can be used to optimum the microstructural design of the coating so as to improve the adhesion of zinc coatings on the steel.

\section{Acknowledgements}

This research was carried out under the project "Fundamentals in the adhesion of physical vapor deposited ZnMg-coatings for the next generation steels" in the Partnership Program High-Tech Materials 2014 (Grant No. 13942, STW, Utrecht, The Netherlands). Financial support from STW is acknowledged. 


\section{References}

[1] Zhang, X., van den Bos, C., Sloof, W.G., Terryn, H., Hovestad, A., \& de Wit, J.H.W., Investigation of Cr(III)-based conversion coatings on electrogalvanized steel, Surf Eng, 20, pp. 244-250, 2004.

[2] De Bruycker, E., De Cooman, B.C. \& De Meyer, M., Galvanizability of complex phase high strength steel, Steel Research Int, 75, pp. 147-15, 2004.

[3] Winand, R., Continuous strip coating: new zinc alloy tailored coatings, Surf Coat Technol, 37, pp. 65-87, 1989.

[4] Nunomura, Y. \& Takasugi, T., Plastic deformation and fracture behavior of galvannealed coating, ISIJ International, 43, pp. 454-460, 2003.

[5] Parisot, R., Forest, S., Pineau, A., Grillon, F., Demonet, X. \& Mataigne, J.M., Deformation and damage mechanisms of zinc coatings on hot-dip galvanized steel sheets: Part II. Damage modes. Metall Mater Trans A, 35A, pp. 813-823, 2004.

[6] Freund, L.B. \& Suresh, S., Thin film materials: stress, defect formation and surface evolution, Cambridge Univ. Press, New York, pp. 220-309, 2003.

[7] Ollendorf, H. \& Schneider, D., A comparative study of adhesion-test methods for hard coatings, Surf Coat Technol, 113, pp. 86-102, 1999.

[8] Sargent, J. P., Microextensometry, the peel test and the influence of adherend thickness on the measurement of adhesive fracture energy, Int $J$ Adhesion \& Adhesives, 18, pp. 215-224, 1998.

[9] Ye, M., Delplancke, J.L., Berton, G., Segers, L. \& Winand, R., Characterization and adhesion strength of $\mathrm{Zn}$ coatings electrodeposited on steel substrates, Surf Coat Technol, 105, pp. 184-188, 1998.

[10] Becker, T.L., McNaney, J.M., Cannon, R.M. \& Rithie, R.O., Limitations on the use of the mixed-mode delaminating beam test specimen: Effects of the size of the region of K-dominance, Mech Mater. 25, pp. 291-308, 1997.

[11] Sanchez, J.M., EL-Mansy, S., Sun, B., et al. Cross-sectional nanoindentation: a new technique for thin film interfacial adhesion characterization, Acta Mater, 47, pp. 4405-4413, 1999.

[12] Gallego, A., Gil, J.F., Vico, J.M., Ruzzante, J.E. \& Piotrkowski, R., Coating adherence in galvanized steel assessed by acoustic emission wavelet analysis, Scripta Mater. 52, pp. 1069-1074, 2005.

[13] Seah, C.H., Mridha, S. \& Chan, L.H., Adhesive strength of electroplated copper films, J Mater Proc Tech. 114, pp. 252-256, 2001.

[14] Agrawal, D.C. \& Raj, R., Measurement of the ultimate shear strength of a metal-ceramic interface, Acta Metall, 37, pp. 1265-1270, 1989.

[15] Hertveldt, I., De Cooman, B.C., Meseure, K. \& Xhoffer, C., The shear strength of galvannealed coatings on IF steels. ISIJ International, 39, pp. 1280-1288, 1999. 
[16] De Bruycker, E., De Cooman, B.C. \& De Meyer, M., Galvanizability of complex phase high strength steel, Steel Research Int, 75, pp. 147-152, 2004.

[17] Hutchinson, J.W. \& Suo, Z., Mixed mode cracking in layered materials, Adv Appl Mech, 29, pp. 63-191, 1992.

[18] Parisot, R., Forest, S., Pineau, A., Grillon, F., Demonet, X. \& Mataigne, J.M., Deformation and damage mechanisms of zinc coatings on hot-dip galvanized steel sheets: Part 1. Deformation modes, Metall Mater Trans A, 35A, 797-811, 2004.

[19] Nunomura, Y. \& Takasugi, T., Plastic deformation and fracture behavior of galvannealed coating, ISIJ international, 43, pp. 454-460, 2003.

[20] De Cooman, B.C., Structure-properties relationship in TRIP steels containing carbide-free bainite, Curr Opin Solid State Mat Sci, 8, pp. 285303, 2004.

[21] Mintz, B., Hot dip galvanizing of transformation induced plasticity and other intercritically annealed steels, Int Mater Rev, 46, pp. 169-197, 2001.

[22] Mahieu, J., Claessens, S. \& De Cooman, B.C., Galvanizability of high strength steels for automotive application, Metall Mater Trans A, 32A, 2905-2908, 2001.

[23] Mahieu, J., Claessens, S., De Cooman, B.C. \& Goodwin, F., Surface and subsurface characterization of Si-, Al- and P-alloyed TRIP-aided steel, Galvatech '04 conference Proceedings, Chicago, USA, pp. 529-538, 2004.

[24] Song, G.M., Sloof, W.G., Vystavel, T. \& De Hosson, J.Th.M., Interface microstructure and adhesion of zinc coatings on TRIP steels, Materials Forum, 539-543, pp. 1104-1109, 2007.

[25] Dao, M., Chollacoop, N., Van Vliet, K.J., Venkatesh, T.A. \& Suresh, S., Computational modeling of the forward and reverse problems in instrumented sharp indentation, Acta Mater, 49, pp. 3899-3918, 2001.

[26] Hibbeler, R.C., Mechanics of Materials, 3rd ed. Prentice-Hall, Englewood Cliffs, NJ, USA, 1997.

[27] Hanson, A.W., Elastic behavior and elastic constants of zinc single crystals, Phys Rev. 45, pp. 324-331, 1933.

[28] Pei, Y.T., Song, G.M., Sloof, W.G. \& De Hosson, J.Th.M., A methodology to determine anisotropy effects in non-cubic coatings. Surf Coat Technol, 201, pp. 6911-6916, 2007.

[29] Fluhrer, J., Deform 2D 8.1 version user's manual, Scientific Forming Technologies Corporation, 2004.

[30] Ochiai, S., Iwamoto, S., Tomida, T., Nakamura, T., Okuda, H., Tanaka, M., \& Hojo, M., Multiple-cracking phenomenon of the galvannealed coating layer on steels under thermal and tensile stresses, Metall Mater Trans A, 36A, pp. 1807-1816, 2005.

[31] Song, G.M., Sloof, W.G., Pei, Y.T. \& De Hosson, J.Th.M., Interface fracture behavior of zinc coatings on steel: experiments and finite element calculations, Surf Coat Technol, 201, pp. 4311-4316, 2006. 